\title{
Sources and transformations of particle-bound polycyclic aromatic hydrocarbons in Mexico City
}

\author{
L. C. Marr ${ }^{1,2}$, K. Dzepina ${ }^{3}$, J. L. Jimenez ${ }^{3}$, F. Reisen ${ }^{4}$, H. L. Bethel ${ }^{4}$, J. Arey ${ }^{4}$, J. S. Gaffney ${ }^{5}$, N. A. Marley ${ }^{5}$, \\ L. T. Molina ${ }^{2}$, and M. J. Molina ${ }^{2, *}$ \\ ${ }^{1}$ Dept. of Civil and Environmental Engineering, Virginia Polytechnic Inst. and State Univ., Blacksburg, Virginia, USA \\ ${ }^{2}$ Dept. of Earth, Atmospheric, and Planetary Sciences, Massachusetts Inst. of Technology, Cambridge, Massachusetts, USA \\ ${ }^{3}$ Dept. of Chemistry and Biochemistry, and Cooperative Inst. for Research in Environmental Sciences (CIRES), Univ. of \\ Colorado, Boulder, Colorado, USA \\ ${ }^{4}$ Air Pollution Research Center and Department of Environmental Sciences, Univ. of California, Riverside, USA \\ ${ }^{5}$ Argonne National Laboratory, Illinois, USA \\ *now at: Dept. of Chemistry and Biochemistry, Univ. of California, San Diego, USA
}

Received: 18 October 2005 - Published in Atmos. Chem. Phys. Discuss.: 13 December 2005

Revised: 9 March 2006 - Accepted: 21 March 2006 - Published: 23 May 2006

\begin{abstract}
Understanding sources, concentrations, and transformations of polycyclic aromatic hydrocarbons (PAHs) in the atmosphere is important because of their potent mutagenicity and carcinogenicity. The measurement of particlebound PAHs by three different methods during the Mexico City Metropolitan Area field campaign in April 2003 presents a unique opportunity for characterization of these compounds and intercomparison of the methods. The three methods are (1) collection and analysis of bulk samples for time-integrated gas- and particle-phase speciation by gas chromatography/mass spectrometry; (2) aerosol photoionization for fast detection of PAHs on particles' surfaces; and (3) aerosol mass spectrometry for fast analysis of size and chemical composition. This research represents the first time aerosol mass spectrometry has been used to measure ambient PAH concentrations and the first time that fast, real-time methods have been used to quantify PAHs alongside traditional filter-based measurements in an extended field campaign. Speciated PAH measurements suggest that motor vehicles and garbage and wood burning are important sources in Mexico City. The diurnal concentration patterns captured by aerosol photoionization and aerosol mass spectrometry are generally consistent. Ambient concentrations of particlephase PAHs typically peak at $\sim 110 \mathrm{ng} \mathrm{m}^{-3}$ during the morning rush hour and rapidly decay due to changes in source activity patterns and dilution as the boundary layer rises, although surface-bound PAH concentrations decay faster. The more rapid decrease in surface versus bulk PAH concentra-
\end{abstract}

Correspondence to: L. C. Marr

(lmarr@vt.edu) tions during the late morning suggests that freshly emitted combustion-related particles are quickly coated by secondary aerosol material in Mexico City's atmosphere and may also be transformed by heterogeneous reactions.

\section{Introduction}

Polycyclic aromatic hydrocarbons (PAHs) are a class of semi-volatile compounds formed as a byproduct of incomplete combustion and emitted by sources such as motor vehicles, coal-fired power plants, wood fires, and cigarettes. Many PAHs are potent mutagens and carcinogens, and they account for the majority of mutagenic potency attributable to specific compounds in ambient particulate matter (Hannigan et al., 1998). The PAH benzo[a]pyrene has been directly linked to lung cancer through its selective formation of adducts along a tumor suppressor gene (Denissenko et al., 1996).

Transformations of PAHs on particles have the potential to affect the particles' toxicity through the formation of species that are more toxic, e.g. nitro-PAH (Sasaki et al., 1997), or less toxic. Heterogeneous reactions of particulate PAHs (Bertram et al., 2001; Esteve et al., 2003, 2004, 2006) may serve as surrogates for heterogeneous chemistry of many types of organics; such reactions could change the particles' hydrophilicity and thus their potential to act as cloud condensation nuclei (Jones et al., 2004). A second mechanism of transformation is coating of freshly emitted particles by condensation of secondary aerosol components formed by gas-phase reactions. Through this type of transformation,

Published by Copernicus GmbH on behalf of the European Geosciences Union. 
PAHs that are initially present on the surface of particles may become less accessible for heterogeneous reactions and less bioavailable. PAHs are associated with black carbon, and coating of such particles has significant implications for radiative forcing and climate change (Chandra et al., 2004; Conant et al., 2003; Jacobson, 2001).

In the spring of 2003, a multinational team of over 100 atmospheric scientists from 30 Mexican, US, and European institutions conducted an intensive five-week field campaign in the Mexico City Metropolitan Area (MCMA) (de Foy et al., 2005). The overall goals of the effort were to contribute to the understanding of the air quality problem in Mexico City and to serve as a model for the study of other megacities in the developing world. Recent studies of PAHs in Mexico City have reported concentrations there to be among the highest measured anywhere in the world. Median total particle-bound PAH concentrations along Mexico City's roadways range from 50 to $910 \mathrm{ng} \mathrm{m}^{-3}$, equivalent to smoking 0.4 cigarettes per hour or a lung cancer risk level of $2 \times 10^{-5}$ for $10 \mathrm{~h}$ per week of exposure over 40 years (Marr et al., 2004; Velasco et al., 2004). The extremely high ambient concentrations in Mexico City provide a stronger signal for the analysis of diurnal patterns and comparison against concentrations of related pollutants. Comparison of PAH versus elemental carbon and active surface area concentrations in Mexico City suggests that surface PAH concentrations may diminish rapidly with particle aging (Marr et al., 2004). Because of the serious health effects of PAHs, it is important to understand their sources and losses under ambient conditions.

The measurement of particle-bound PAHs by three different methods - filters, aerosol photoionization, and aerosol mass spectrometry - during the five-week MCMA field campaign allows a more comprehensive characterization of these compounds in ambient air than has been possible in the past. Combined with measurements of numerous other species, including gas-phase PAHs, the data present a unique opportunity to characterize ambient concentrations, sources, and atmospheric processing of PAHs. This research represents the first time aerosol mass spectrometry has been used to measure ambient PAH concentrations and the first time that two fast, real-time methods have been used to quantify PAHs alongside traditional filter-based measurements in an extended field campaign. The objectives of this research are to (1) compare and contrast the three measurement methods, (2) describe the ambient concentrations and sources of PAHs in Mexico City, and (3) explain the differences in diurnal patterns observed in PAH versus other species concentrations.

\section{Experimental}

The measurements took place on the rooftop ( $12 \mathrm{~m}$ above ground level) of a three-story building at the Universidad Autónoma Metropolitana in Iztapalapa (UAM-I), approxi- mately $10 \mathrm{~km}$ southeast of downtown Mexico City, whose elevation is $2240 \mathrm{~m}$. The building houses the National Center for Environmental Research and Education, and the site is known by its Spanish acronym, CENICA. The site is located in a mixed-used medium-income neighborhood with light traffic. The nearest major roads are at least $1 \mathrm{~km}$ away.

The five-week field campaign took place toward the end of the dry season during April 2003. It included Holy Week, which ended with Easter Sunday on 20 April. During the holiday week, many businesses closed and residents left on vacation. The average temperature during the field campaign was $21^{\circ} \mathrm{C}$, with an average daily low of $15^{\circ} \mathrm{C}$ and high of $29^{\circ} \mathrm{C}$. Winds were often northerly in the morning and southerly in the evening, with an average speed of $2 \mathrm{~m} \mathrm{~s}^{-1}$. Rain occurred, usually briefly and in the afternoon and early evening, on 7, 8, 10, 12, 20, 22, 25, and 28 April.

Particle-bound PAHs were measured by three methods: (1) filter collection and analysis by gas chromatography/mass spectrometry (GC/MS), (2) aerosol photoionization, and (3) aerosol mass spectrometry. The "total" particulate PAH concentrations, defined in Table 1, measured by each method are referred to as FPAH, SPAH, and APAH, respectively. The method intercomparison focuses on a three-day period, 2730 April. The filter sampler and photoionization aerosol sensor were located on opposite sides of an experimental platform, approximately $3 \mathrm{~m}$ apart and $4 \mathrm{~m}$ above the rooftop. The aerosol mass spectrometer was housed in a temperaturecontrolled storage building at the opposite end of the rooftop, approximately $50 \mathrm{~m}$ from the experimental platform. Due to physical limitations of the site, a shared sampling line was not feasible, so long tubing with its potential for diffusional losses of particles was not a factor in this intercomparison. Although the three methods were located at different points on the rooftop, they were believed to be sampling from the same air mass, as verified by the simultaneous detection of short-term spikes in ambient concentrations by the two realtime instruments located at opposite ends of the building.

\subsection{Time-integrated sampling and speciated analysis}

For the speciation of PAHs by GC/MS, time-averaged bulk samples were collected on 27-30 April. A high-volume (Hivol) air sampler equipped with a Teflon-impregnated glass fiber filter $(20 \mathrm{~cm} \times 25 \mathrm{~cm})$ and two polyurethane foam plugs (PUFs) in series beneath the filter and without a size-selective inlet was used to collect semi-volatile and particle-associated PAHs at a flow rate of $\sim 0.6 \mathrm{~m}^{3} \mathrm{~min}^{-1}$. Gas-phase naphthalene and alkyl-naphthalenes were simultaneously collected on replicate Tenax-TA solid adsorbent cartridges at a flow rate of $200 \mathrm{~cm}^{3} \mathrm{~min}^{-1}$. Samples were collected over four sampling intervals per 24-h period: 07:00-11:00, 11:0016:00, 16:00-21:00, and an overnight sample from 21:0007:00.

The filter and PUF samples were spiked with deuterated internal standards, Soxhlet extracted overnight in 
Table 1. Particulate PAHs quantified by each method.

\begin{tabular}{|c|c|c|c|c|}
\hline Species & M & GC/MS & PAS $^{\mathrm{a}}$ & $\mathrm{AMS}^{\mathrm{b}}$ \\
\hline Acephenanthrylene & 202 & $\mathrm{FPAH}^{* \mathrm{c}}$ & SPAH & APAH* \\
\hline Fluoranthene & 202 & FPAH* $^{*}$ & SPAH & APAH* \\
\hline Pyrene & 202 & FPAH $^{*}$ & SPAH & APAH $^{*}$ \\
\hline 1,2-Benzofluorene & 216 & FPAH & & APAH \\
\hline 2,3-Benzofluorene & 216 & FPAH & & APAH \\
\hline 1-Methylpyrene & 216 & FPAH & & APAH \\
\hline Methylated MW 216 species (4 isomers in FPAH) & 216 & $\mathrm{FPAH}^{\mathrm{c}}$ & & APAH \\
\hline Benzo[ghi]fluoranthene & 226 & FPAH $^{*}$ & SPAH & APAH* \\
\hline Cyclopenta[cd]pyrene & 226 & FPAH $^{*}$ & SPAH & APAH* $^{*}$ \\
\hline Benz[a]anthracene & 228 & FPAH $^{*}$ & SPAH & APAH* $^{*}$ \\
\hline Benzo[c]phenanthrene & 228 & & SPAH & APAH* \\
\hline Chrysene/triphenylene & 228 & FPAH $^{*}$ & SPAH & APAH* \\
\hline Retene (1-methyl-7-isopropyl-phenanthrene) & 234 & FPAH & & \\
\hline Methylated MW 226 species ( 3 isomers in FPAH) & 240 & $\mathrm{FPAH}^{\mathrm{c}}$ & & APAH \\
\hline Methylated MW 228 species (10 isomers in FPAH) & 242 & $\mathrm{FPAH}^{\mathrm{c}}$ & & APAH \\
\hline Benzo $[b+j+k]$ fluoranthenes & 252 & FPAH $^{*}$ & SPAH & APAH* \\
\hline Benzo[a]pyrene & 252 & FPAH $^{*}$ & SPAH & APAH* \\
\hline Benzo[e]pyrene & 252 & FPAH* $^{*}$ & SPAH & APAH* \\
\hline Perylene & 252 & $\mathrm{FPAH}^{* \mathrm{c}}$ & SPAH & APAH* $^{*}$ \\
\hline 11H-Cyclopenta[ghi]perylene & 264 & & & APAH \\
\hline 4H-Benzo[hi]chrysene & 266 & & & APAH \\
\hline Benzo[ghi]perylene & 276 & FPAH $^{*}$ & SPAH & APAH* \\
\hline Indeno[1,2,3-cd]pyrene & 276 & FPAH $^{*}$ & SPAH & APAH* \\
\hline 1H-Benzo[ghi]yclopenta[pqr]perylene & 288 & & & APAH \\
\hline 9H-Indeno[1,2-e]pyrene & 290 & & & APAH \\
\hline Coronene & 300 & FPAH $^{*}$ & SPAH & APAH* \\
\hline 1,3,5-Triphenylbenzene & 306 & FPAH & & \\
\hline
\end{tabular}

* These species are included in the modified FPAH* and APAH* totals which are intended for comparison to SPAH.

a The PAS response, denoted SPAH here, has been calibrated against the sum of these PAHs. The signal is influenced by ionization potential and molecular size (Niessner, 1986).

$\mathrm{b}$ The AMS response includes $[\mathrm{M}],\left[\mathrm{M}-\mathrm{H}_{n}\right]$ (where $\left.\mathrm{n}=1-4\right)$, and $[\mathrm{M}+1]$ ions but does not differentiate between isomers. Thus, the PAHs shown as contributing to APAH are only examples of those at a certain M that should be detectable by this method.

${ }^{\mathrm{c}}$ Identifications are based upon retention indices for these species. In all other cases, individual standards were available to determine retention times and mass spectra.

dichloromethane, fractionated by high performance liquid chromatography (HPLC) on a semipreparative Silica column, and the PAH-containing fractions were analyzed by GC/MS. The PUFs were spiked with phenanthrene- $\mathrm{d}_{10}$, fluoranthene- $\mathrm{d}_{10}$ and pyrene- $\mathrm{d}_{10}$ prior to extraction and were analyzed by positive ion/chemical ionization GC/MS with selected ion monitoring (SIM) using a DB-17 column in an Agilent 5973 mass selective detector (MSD). Filters were spiked with pyrene- $\mathrm{d}_{10}$, benzo[b]fluoranthene- $\mathrm{d}_{12}$ and benzo[a]pyrene- $d_{12}$ prior to extraction and were analyzed by electron impact (EI) GC/MS-SIM using a DB-5MS column in a Hewlett Packard 5971A MSD. The Tenax samples were spiked with naphthalene- $\mathrm{d}_{8}$ and 1-methylnaphthalene$\mathrm{d}_{10}$ prior to thermal desorption and EI GC/MS-SIM analysis as described previously (Reisen and Arey, 2005). Table 1 lists the particle-phase species identified on filters (FPAH).

\subsection{Aerosol photoionization}

The main advantages of aerosol photoionization are its sensitivity and ability to perform continuous, real-time measurements with a response time of less than $10 \mathrm{~s}$. In this method, the aerosol sample is exposed to ultraviolet light from an excimer lamp at $207 \mathrm{~nm}$, which causes PAHs on the surface of particles to photoemit electrons. An electric field removes the ejected electrons, and the positively charged particles are trapped on a filter, generating a current that is measured by an electrometer.

The photoelectric aerosol sensor (PAS 2000 CE, EcoChem Analytics, Texas, and Matter Engineering AG, Switzerland) reports results as total particle-bound PAHs. Because our experience suggests that the instrument is most sensitive to PAHs on the surfaces of particles and less sensitive to those buried under other aerosol compounds, we henceforth use 


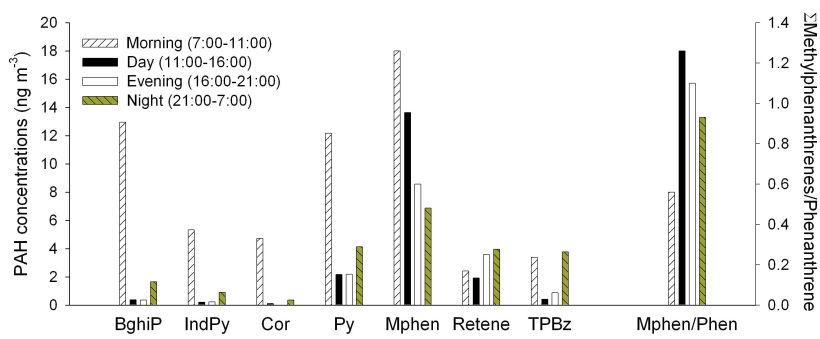

Fig. 1. Concentrations (gas + particle phases) of benzo[ghi]perylene (BghiP), indeno[1,2,3-cd]pyrene (IndPy), coronene (Cor), pyrene (Py), methylphenanthrenes (Mphen), retene (1-methyl-7-isopropylphenanthrene), and 1,3,5-triphenylbenzene (TPBz) on 29 April 2003. Also shown is the ratio of methylphenanthrenes to phenanthrene (Mphen/Phen), an indicator of the relative contribution of diesel versus gasoline vehicle exhaust. BghiP, IndPy and Cor are markers of gasoline vehicle exhaust, retene of soft wood combustion and TPBz of garbage burning.

"SPAH" to refer to particle-bound surface PAHs detected by the photoionization sensor. "PAH" will continue to refer to the class of compounds more generally. The instrument is factory-calibrated for SPAH concentrations up to $1000 \mathrm{ng} \mathrm{m}^{-3}$, and it is expected to give a linear response up to $5000 \mathrm{ng} \mathrm{m}^{-3}$. The response is calibrated against filterbased analyses of PAHs, including species with molecular masses 202, 226, 228, 252, 276, and 300 (Hart et al., 1993; McDow et al., 1990). Because the energy associated with the PAS lamp $(6.0 \mathrm{eV})$ is less than the ionization energy of solid-phase naphthalene $(6.4 \mathrm{eV})$ (Seki, 1989), the instrument does not detect naphthalene. Previous studies have shown a strong correlation between photoelectric charging and independently measured PAH concentrations for a variety of aerosols: oil burner exhaust, cigarette smoke, parking garage air, and ambient urban air in different cities (Siegmann and Siegmann, 2000). The sensor's response has also been reported to be linearly correlated $\left(r^{2}=0.82\right)$ with bacterial genotoxicity (Wasserkort et al., 1996).

During this study, we cross-calibrated four photoionization sensors against the ensemble mean while sampling candle soot and ambient air at concentrations of 20-3000 $\mathrm{ng} \mathrm{m}^{-3}$ for 5-30 min on four separate occasions. All instruments reported a concentration of zero with a zero-air filter applied. Correction factors for the individual instruments ranged from 0.82 to 1.34 . From our experience with the PAS in this and a previous field campaign (Marr et al., 2004), we estimate its uncertainty to be $20 \%$. The manufacturer reports a limit of detection of $10 \mathrm{ng} \mathrm{m}^{-3}$ for the analyzer.

\subsection{Aerosol mass spectrometer}

The Aerodyne Aerosol Mass Spectrometer (AMS) allows real-time, size and composition analysis of non-refractory submicron particles (Jayne et al., 2000; Jimenez et al., 2003). A summary of the main results from the AMS measurements during this field campaign is given by Salcedo et al. (2006). A separate paper (Dzepina et al., 2006 ${ }^{1}$ ) describes in detail the algorithm for extracting particle-phase PAH concentrations from AMS spectra and its validation. Here, we report the total AMS PAH concentration (APAH), which represents the sum of the concentrations of PAHs between molecular weights of 202 and 300. While the AMS can identify PAHs by their molecular masses, it does not differentiate between isomers.

We also report a modified total APAH (APAH*) to facilitate comparison against SPAH. The modified total includes only PAHs with molecular masses of 202, 226, 228, 252, 276, and 300, as shown in Table 1. It excludes signals at molecular masses of 216, 240, 242, 264, 266, 288, and 290 that correspond to alky-PAHs and/or PAHs with partially saturated rings (such as, $11 \mathrm{H}$-cyclopenta[ghi]perylene), because the photoionization instrument's calibration does not account for such species. This modification also excludes benzofluorenes, but their contribution is at most $3 \%$ of the FPAH total.

The limit of detection, estimated as three times the standard deviation of the reported concentrations when the AMS was sampling ambient air through a filter, is $36 \mathrm{ng} \mathrm{m}^{-3}$ for total APAH and $24 \mathrm{ng} \mathrm{m}^{-3}$ for the modified total APAH* over a 4-min measurement period. Detection limits scale with the inverse of the square root of the averaging time, so over 15min periods, these limits will be 19 and $12 \mathrm{ng} \mathrm{m}^{-3}$ for APAH and $\mathrm{APAH}^{*}$, respectively. Uncertainties in the method due to systematic and random errors, described in greater detail in Dzepina et al. (2006), are $+45 \%$ and $-35 \%$ of the reported concentration.

\subsection{Additional measurements}

Black carbon and PAHs form during the same combustion processes. Their concentrations are correlated in ambient air, and are impacted by a variety of combustion sources, including traffic, cooking, and wood smoke (Marr et al., 2004; Schauer et al., 2003; Wallace, 2000; Watson and Chow, 2002; Zielinska et al., 2004a). A meteorological station located on the experimental platform recorded temperature, humidity, pressure, and wind velocity every minute. The site was part of a routine air quality monitoring network that measured concentrations of criteria pollutants, including sulfur dioxide, carbon monoxide, ozone, nitrogen dioxide, and particulate matter. Black carbon was measured at 4-min frequency by optical attenuation using an aethalometer (Magee Scientific AE-31, Berkeley, California).

\footnotetext{
${ }^{1}$ Dzepina, K., Salcedo, D., Marr, L. C., Arey, J., Worsnop, D. R., and Jimenez, J. L.: Detection of particle-phase polycyclic aromatic hydrocarbons (PAHs) in Mexico City using an Aerosol Mass Spectrometer, Int. J. Mass Spectrometry, submitted, 2006.
} 


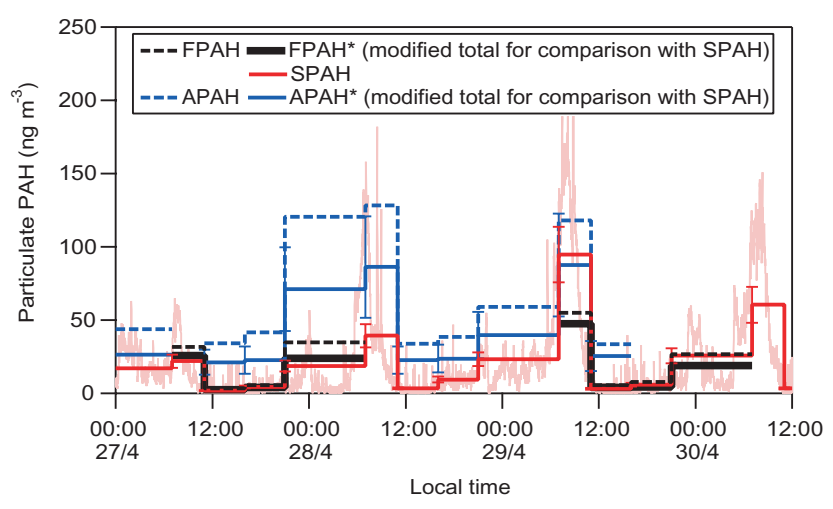

Fig. 2. Particulate PAH concentrations measured using filters (FPAH), photoionization (SPAH), and the AMS (APAH). The background time series shows 1-min SPAH.

\section{Results}

Figure 1 shows concentrations of selected PAHs (gas + particle phases) determined by GC/MS on Tuesday 29 April. These PAHs are shown because of their association with specific sources. As PAHs are semi-volatile, some of the particle-phase compounds may have been emitted originally as gases in hot exhaust and then may have condensed onto existing particles as the mixture cooled. Studies of vehicle emissions have shown that larger PAHs, in particular benzo[ghi]perylene, indeno[1,2,3-cd]pyrene, and coronene, are emitted in gasoline-fueled vehicle exhaust (Marr et al., 1999; Miguel et al., 1998; Zielinska et al., 2004b), while alkylated phenanthrenes are associated with diesel vehicles (Benner et al., 1989). Concentrations of benzo[ghi]perylene and methylphenanthrenes are highest in the morning, although the diurnal patterns of these two PAHs differ. Benzo[ghi]perylene concentrations are 36 times higher in the morning compared to the afternoon and evening, while methylphenanthrene concentrations are only 1-2 times higher in the morning. As seen in Fig. 1, the diurnal patterns of indeno[1,2,3-cd]pyrene and coronene are similar to that of benzo[ghi]perylene.

A GC/MS total ion chromatogram of the PAH-containing HPLC fraction from a filter sample revealed a retene peak and also a large peak from a MW 306 species. Retene has been suggested as a marker for soft wood combustion (Ramdahl, 1983). The MW 306 species was subsequently identified to be 1,3,5-triphenylbenzene by matching its mass spectra and retention time on two different GC columns with those of an authentic standard. This compound has recently been suggested to be a potential marker for the burning of refuse, including plastics (Simoneit et al., 2005). In contrast to the other PAHs, which are all considered markers of vehicle exhaust, the 1,3,5-triphenylbenzene and retene concentrations are highest in the nighttime rather than morning or daytime samples.

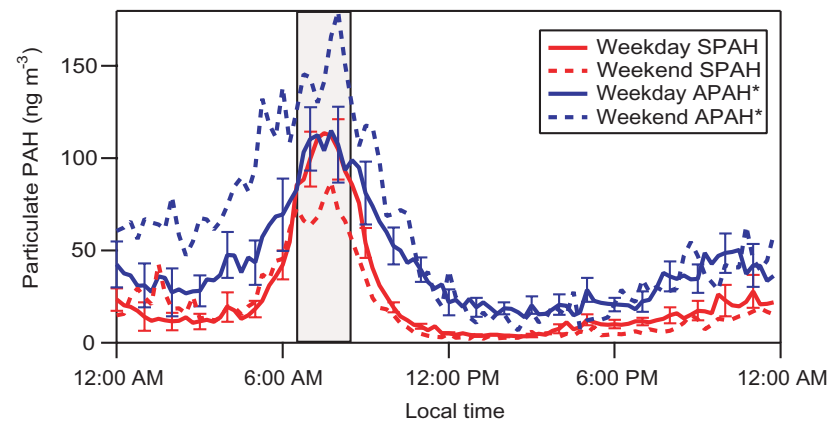

Fig. 3. Non-holiday weekday and weekend diurnal cycles of SPAH and $\mathrm{APAH}^{*}$ at 15-min resolution. The shaded area highlights the peak rush hour period between 06:30-08:30. Error bars of one standard deviation are shown at 1-h intervals for the weekday time series.

Figure 2 shows total particulate PAH concentrations measured by all three methods during the three days when they were operating simultaneously, 27-30 April. Not all methods were operating during the entire interval. Filter measurements are not available for 28 April, and the AMS was not sampling continuously during this period. All PAHs identified as part of the FPAH total were also seen by the AMS, except for retene and 1,3,5-triphenylbenzene.

In the figure, heavy solid and dotted lines show timeintegrated averages corresponding to the filter sampling periods. To illustrate the fine temporal structure of PAH concentrations, the figure also shows 1-min SPAH in the background. Total (FPAH, SPAH, APAH) and modified (FPAH* and $\mathrm{APAH}^{*}$ ) results represent, respectively, all PAHs detected by each method and a modified total, delineated in Table 1 and intended to facilitate comparison against SPAH.

The 1-min SPAH time series shows a strong diurnal pattern in ambient PAH concentrations, with concentrations generally starting to rise at $\sim 05: 00$, peaking at $\sim 08: 00$, and then dropping throughout the late morning. Peak concentrations often exceed $100 \mathrm{ng} \mathrm{m}^{-3}$, and concentrations usually remain below $50 \mathrm{ng} \mathrm{m}^{-3}$ throughout the remainder of the day. However, on the first day shown in the figure, a Sunday, peak concentrations are about $50 \%$ lower compared to the other days.

To facilitate interpretation of future studies using the PAS or AMS for measurement of PAHs, we compare total PAH concentrations determined by all three methods in Table 2 . The totals shown for FPAH and APAH include all particlephase PAHs detected by the filter and AMS methods, respectively. The table also shows ratios of SPAH and APAH to the more traditional FPAH. The ratio SPAH/FPAH falls in the range 0.5-1.0, except for one period on a weekday morning when the ratio is 1.7. The ratio APAH/FPAH ranges between 2.1-10, with the poorest agreement when PAH concentrations are low. 
Table 2. Total particle-phase PAH concentrations $\left(\mathrm{ng} \mathrm{m}^{-3}\right)$ measured by filters (FPAH), aerosol photoionization (SPAH), and aerosol mass spectrometry (APAH).

\begin{tabular}{llllll}
\hline Time & FPAH $^{\mathrm{a}}$ & SPAH $^{\mathrm{a}}$ & APAH $^{\mathrm{b}}$ & SPAH/FPAH & APAH/FPAH \\
\hline 27 April (Sun) & & & & & \\
07:00-11:00 & $32 \pm 6$ & $22 \pm 4$ & N/A & $0.69 \pm 0.20$ & N/A \\
11:00-16:00 & $3 \pm 1$ & $2 \pm 0^{\mathrm{c}}$ & $34 \pm 14$ & $0.6 \pm 0.2$ & $10 \pm 5$ \\
16:00-21:00 & $6 \pm 1$ & $5 \pm 1^{\mathrm{c}}$ & $42 \pm 17$ & $0.9 \pm 0.2$ & $7 \pm 3$ \\
21:00-7:00 & $35 \pm 7$ & $19 \pm 4$ & $121 \pm 48$ & $0.55 \pm 0.15$ & $3.5 \pm 1.6$ \\
29 April (Tue) & & & & & \\
07:00-11:00 & $55 \pm 11$ & $95 \pm 19$ & $118 \pm 47$ & $1.7 \pm 0.5$ & $2.1 \pm 1.0$ \\
11:00-16:00 & $6 \pm 1$ & $3 \pm 1^{\mathrm{c}}$ & $33 \pm 13$ & $0.5 \pm 0.2$ & $6 \pm 3$ \\
16:00-21:00 & $8 \pm 2$ & $6 \pm 1^{\mathrm{c}}$ & N/A & $0.8 \pm 0.2$ & N/A \\
21:00-7:00 & $27 \pm 5$ & $26 \pm 5$ & N/A & $1.0 \pm 0.3$ & N/A \\
\hline
\end{tabular}

a Overall uncertainty is estimated to be $20 \%$.

b Overall uncertainty is estimated to be $40 \%$.

${ }^{\mathrm{c}}$ Below detection limit.

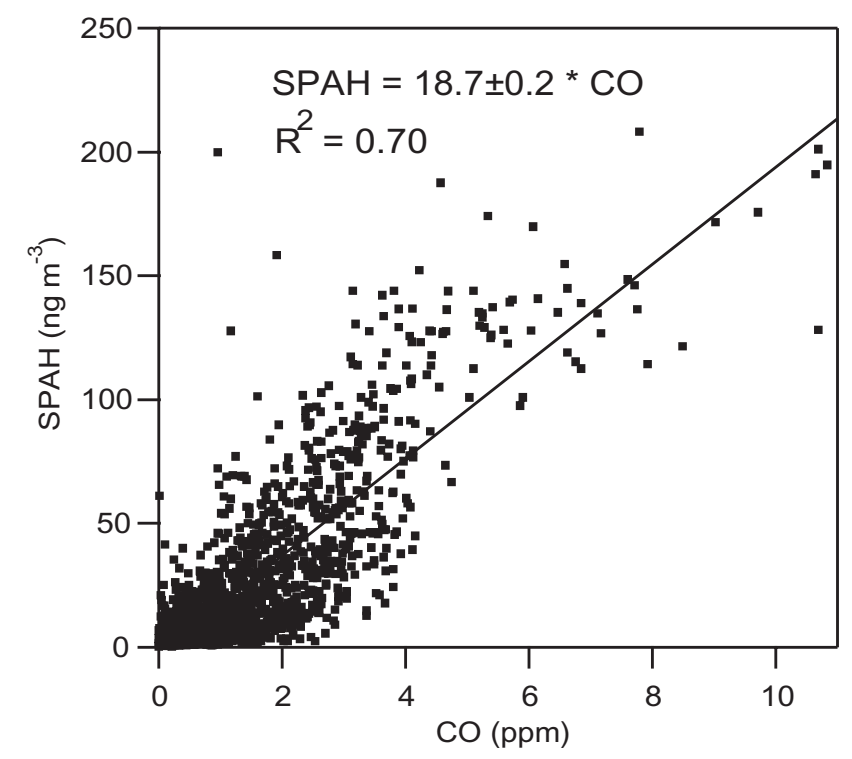

Fig. 4. SPAH versus $\mathrm{CO}$ concentrations, 15-min averages. The uncertainty in the measurements is estimated to be $20 \%$ for SPAH and $0.1 \mathrm{ppm}$ for $\mathrm{CO}$.

Figure 3 shows the diurnal profiles (15-min averages) of SPAH and APAH* averaged over weekdays (20 days) and weekends (8 days) separately, excluding Thursday 17 April through Easter Sunday 20 April, when traffic and ambient pollutant concentrations were significantly lower than usual. Error bars in the figure show one standard deviation at 1$\mathrm{h}$ intervals for the weekday time series. We have isolated weekdays because motor vehicle activity, thought to be a major source of PAHs, is expected to differ significantly between weekdays and weekends (Marr et al., 2002). The tem- poral patterns of SPAH and APAH* are similar, with concentrations beginning to increase at 05:00, peaking at 08:00, and then falling off; but their absolute values differ during most hours of the day. On weekdays, SPAH is usually lower than APAH* by $\sim 20 \mathrm{ng} \mathrm{m}^{-3}$, except during the peak period (06:30-08:30), when the two signals are comparable in magnitude. Linear, least-squares regression of the weekday diurnal profiles of $\mathrm{APAH}^{*}$ against SPAH produces a slope of $0.86 \pm 0.03$ (standard deviation) and intercept of $21 \pm 1 \mathrm{ng} \mathrm{m}^{-3}$ with $r^{2}=0.87$. An additional difference between the two is that $\mathrm{APAH}^{*}$ does not seem to decay as fast as SPAH in the late morning.

The differences in weekday versus weekend concentrations are opposite for the two measurements of PAH concentration. Weekend SPAH concentrations are $\sim 30 \%$ lower compared to weekday SPAH during the peak morning rush hour period, but weekend APAH* concentrations are up to two times higher compared to weekday APAH* between midnight and 11:00. Weekend APAH* is approximately twice as high as weekend SPAH, with a regression slope of $1.85 \pm 0.09$, intercept of $21 \pm 3 \mathrm{ng} \mathrm{m}^{-3}$, and $r^{2}=0.81$. Because weekend days are fewer, the standard deviations of the weekend time series, not shown for reasons of legibility, overlap between SPAH and APAH*.

SPAH is strongly correlated with both $\mathrm{CO}$ and gasphase naphthalene. Figure 4 shows 15 -min averages of SPAH versus $\mathrm{CO}$ during the entire field campaign. The slope of the regression line, forced through zero, is $18.7 \pm 0.2 \mathrm{ng} \mathrm{m}^{-3} \mathrm{ppm}^{-1}$, with $r^{2}=0.70$. Figure 5 shows SPAH versus all available naphthalene measurements $(\mathrm{n}=24)$, which are time-integrated over 4 - to 10 -h periods. For the relationship between SPAH and naphthalene, the slope is $0.034 \pm 0.001$ with $r^{2}=0.92$. 


\section{Discussion}

\subsection{Method intercomparison}

The three PAH measurement techniques have complementary strengths. Collection of time-integrated samples with GC/MS analysis allows detailed, isomer-specific speciation and the ability to quantify both gas- and particle-phase concentrations. Aerosol photoionization is a sensitive and fast technique that detects total surface PAH concentrations. Aerosol mass spectrometry provides speciation by MW, estimated size distributions, and measures of other nonrefractory submicron aerosol components at 4-min resolution.

While the three methods generally report similar trends and the same order of magnitude for the concentrations, certain disparities may emphasize methodological limitations, transformation of PAHs, and/or uncertainties in calibration. Figures 2 and 3 show that APAH* is generally higher than SPAH, except during the morning rush hour between 06:3008:30 when they are similar. The differences exceed the methodological uncertainty bounds during 7 of the 11 overlapping periods in Fig. 2 and exceed one standard deviation in the diurnal averages between 03:00-05:00 and between 09:00-23:00 in Fig. 3. The likely cause of lower SPAH values is the fact that the PAS responds only to surface-bound PAHs. The difference in mass loadings is also captured in the large intercept $\left(\sim 21 \mathrm{ng} \mathrm{m}^{-3}\right)$ of the correlation between APAH* $^{*}$ and SPAH. As the particles are coated by condensation of the products of the active photochemistry in Mexico City (Shirley et al., 2005; Volkamer et al., 2005), the photoionization sensor becomes blind to the "buried" PAHs while the AMS, which fully vaporizes the non-refractory portion of the particles (Slowik et al., 2004), continues to detect them. This leads to higher PAH measurements with the AMS when aged particles dominate, i.e. during most of the day except the morning rush hour.

An intriguing observation is that while SPAH concentrations are higher on weekdays than on weekends, $\mathrm{APAH}^{*}$ concentrations are actually higher on weekends, particularly between midnight and 11:00. The difference may not be significant, as the standard deviations of these averages are large and do in fact overlap. Concentrations of carbon monoxide ( $\mathrm{CO})$ and black carbon (BC), indicators of gasoline and diesel engine activity, respectively, are not higher on Friday and Saturday nights and are not significantly different on weekends versus weekdays; so vehicle traffic does not appear to be the cause of higher APAH* on weekends. Instead, sources of emissions that produce particles containing coated PAHs may be important on Friday and Saturday nights (Saturday and Sunday early mornings).

During periods with PAH loadings below $30 \mathrm{ng} \mathrm{m}^{-3}$, FPAH $^{*}$ and SPAH agree well, as shown in Fig. 1. During periods of elevated PAH loadings (07:00-11:00 on Sunday 27 April and 21:00-07:00 on 27-28 April), FPAH* is higher

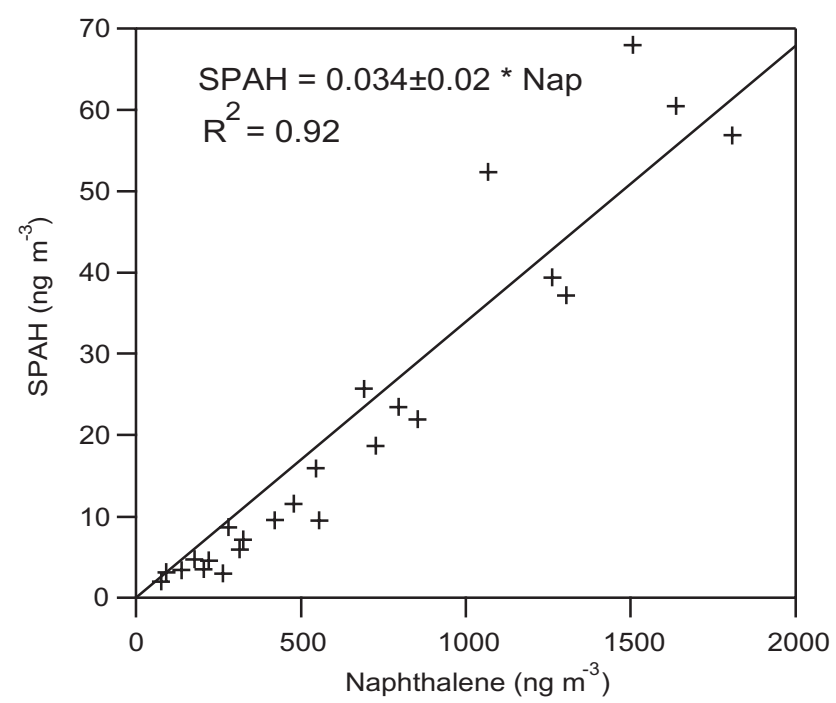

Fig. 5. SPAH versus naphthalene (gas-phase) concentrations. The uncertainty in SPAH is estimated to be $20 \%$. Naphthalene was collected on Tenax in replicate with an average relative standard deviation of $8 \%$.

than SPAH, except during one period dominated by fresh emissions (07:00-11:00 Tuesday 29 April). Again, SPAH may be lower because it does not include PAHs on aged particles that have been coated by secondary aerosol. During the period of fresh emissions when SPAH is higher, the PAHs captured on the filters are exposed to several hours of ambient air during the MCMA's most photochemically active period, i.e. weekday mornings; and the PAHs may be subject to reaction artifacts in the sampler. This type of degradation can reduce PAH concentrations by $50 \%$ for $1-2$ day sampling periods with 70-80 ppb ozone levels (Schauer et al., 2003). The susceptibility to artifactual degradation during FPAH sampling varies among individual PAH species (Arey, 1998; Sanderson and Farant, 2005), and lower FPAH v. APAH values for certain PAHs have been found (Dzepina et al., 2006 ${ }^{1}$ ). The real-time SPAH and APAH measurements are much less susceptible to such artifacts. A second source of uncertainty in the FPAH measurements is volatilization of PAHs from particles captured on the filters. The amount of PAHs captured on PUFs varies between $15-70 \%$ of the total FPAH concentration.

In spite of considerable uncertainties, the three methods often report similar PAH concentrations, and disparities likely reflect methodological differences. While SPAH

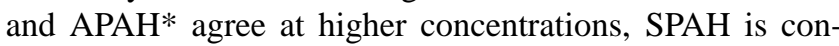
sistently lower than APAH* at lower loadings. In contrast, SPAH and FPAH* agree better at lower concentrations. Due to sampling uncertainties, FPAH should be considered as a lower limit due to the potential for PAH degradation and volatilization during sampling. Likewise, SPAH represents a lower limit of total particle-phase concentrations; the method 
appears to be sensitive only to those PAHs that are present on particles' surfaces. Finally, uncertainty remains in APAH quantification due to the need to subtract the non-PAH organic background from the AMS signal. The reasons for the disparities are not fully known, and laboratory calibration experiments are needed to explore the differences further.

\subsection{PAH sources}

The limited number of samples and lack of precise information about Mexican source profiles in this study preclude a quantitative source apportionment. However, evidence suggests that motor vehicles are the major source of PAH emissions in Mexico City. Motor vehicles are responsible for 99\% of CO emissions in the area (Secretaría del Medio Ambiente, 2003), and PAH and CO concentrations are correlated, as shown in Fig. 4. The strong correlation between SPAH and gas-phase naphthalene, shown in Fig. 5, may also indicate that vehicles are a key source of particulate PAHs, if Mexico City follows the pattern of Southern California, where vehicles are responsible for $53 \%$ of naphthalene emissions (Lu et al., 2004).

These results provide insight into the diurnal patterns of gasoline- versus diesel-powered vehicles in the MCMA. Benzo[ghi]perylene can be used as a marker of gasolinepowered vehicle activity, as it has the highest particle-phase emission factor of the 16 priority PAHs in light-duty vehicle exhaust but is not detected in heavy-duty diesel exhaust (Marr et al., 1999). During the 07:00-11:00 period, benzo[ghi]perylene accounts for $25 \%$ of the total particlephase PAHs; and during the three remaining periods, it accounts for only $7-8 \%$ of the total. This result suggests that gasoline-powered vehicles are an especially significant source of PAHs during the morning rush hour.

On the other hand, methylphenanthrene can be used as an indicator of diesel exhaust (Westerholm et al., 1991). The relative contribution from diesel exhaust appears to increase during 11:00-16:00 relative to the earlier period, as reflected in methylphenanthrene levels that are of similar magnitude (Fig. 1) or increasing (27 April, data not shown), while concentrations of other PAHs except retene decrease significantly, presumably in response to a rising mixing height and reduced source activity.

The ratio of methylphenanthrenes to phenanthrene (Mphen/Phen) has been utilized in source apportionment studies to estimate the relative contributions of gasoline versus diesel emissions (Lim et al., 1999; Nielsen, 1996). For diesel vehicles, Mphen/Phen ratios of 1.5 for gas-phase emissions (Westerholm et al., 1991) and 1.4-8 for particle-phase emissions (Lim et al., 1999; Takada et al., 1990; Westerholm et al., 1991; Zielinska et al., 2004b) have been reported, while for gasoline vehicles, ratios of 0.2-0.7 (Takada et al., 1990; Westerholm et al., 1988) and most recently a ratio of approximately 1.0 for five in-use "normal particulate matter emitters" (Zielinska et al., 2004b), have been reported. While there are significant variations in reported ratios, and operating parameters such as the engine load are known to affect the ratio (Jensen and Hites, 1983), in general ratios $>1$ have been reported from diesel emission sources.

The major source of methyl-PAHs in emissions is likely to be unburned fuel (Tancell et al., 1995; Williams et al., 1986), and methylphenanthrene and dimethylnaphthalene concentrations $\left(\mu \mathrm{g} \mathrm{g}^{-1}\right)$ in diesel fuel are at least an order of magnitude higher than in gasoline (Zielinska et al., 2004b). While naphthalene is the most abundant PAH in gasoline (Marr et al., 1999; Zielinska et al., 2004b), dimethylnaphthalene concentrations are greater than naphthalene in diesel fuels. So an increase in the diesel contribution is likely to result in increased emissions of methylphenanthrenes and dimethylnaphthalenes and an increase in the ratio of Mphen/Phen and dimethylnaphthalenes/naphthalene. Figure 1 shows that Mphen/Phen is $<1$ during the morning rush hour period and $>1$ during the rest of the day. In addition the dimethylnaphthalenes/naphthalene ratio shows a corresponding increase after the morning rush hour (dimethylnaphthalenes/naphthalene $=0.09,0.29,0.09$ and 0.15 corresponding to the morning, day, evening and night time periods in Fig. 1). These observations are consistent with the dominant contribution of gasoline emissions to particle-phase PAH concentrations during the morning rush hour and with the increased importance of diesel emissions during the rest of the day.

Different diurnal traffic patterns of gasoline- and dieselpowered vehicles can explain these observations. In California, gasoline vehicle traffic peaks during the morning and evening rush hours (Marr et al., 2002). However, diesel vehicle traffic starts out slowly during the traditional morning rush hour and then peaks during the late morning and early afternoon. If this pattern were also true in the MCMA, then we would expect emissions from gasoline vehicles to be higher during the 07:00-11:00 period compared to the 11:00-16:00 period and the opposite effect for diesel vehicles. The observed PAH concentrations support this hypothesis. Additionally Fig. 6 shows that $\mathrm{BC}$, which is associated with diesel exhaust, peaks $1-2 \mathrm{~h}$ later in the morning compared to $\mathrm{CO}$, which is associated with gasoline exhaust.

The diurnal patterns of individual PAH masses, shown by Dzepina et al. $(2006)^{1}$, also suggest that activity patterns for gasoline versus diesel vehicles differ, with diesel vehicle traffic lagging the traditional early morning rush hour. The concentrations of lighter MW PAHs $(\mathrm{m} / \mathrm{z}=202$ and 216) peak one hour later and do not decrease as rapidly compared to concentrations of the heavier MW PAHs. Filter-based measurements of PAHs in a roadway tunnel have shown that gasoline vehicles have higher emission factors of the larger PAHs and that diesel vehicles have higher emission factors of the smaller PAHs (Marr et al., 1999). This fact, combined with diesel vehicle traffic that peaks after the morning rush hour, would produce the observed pattern. 


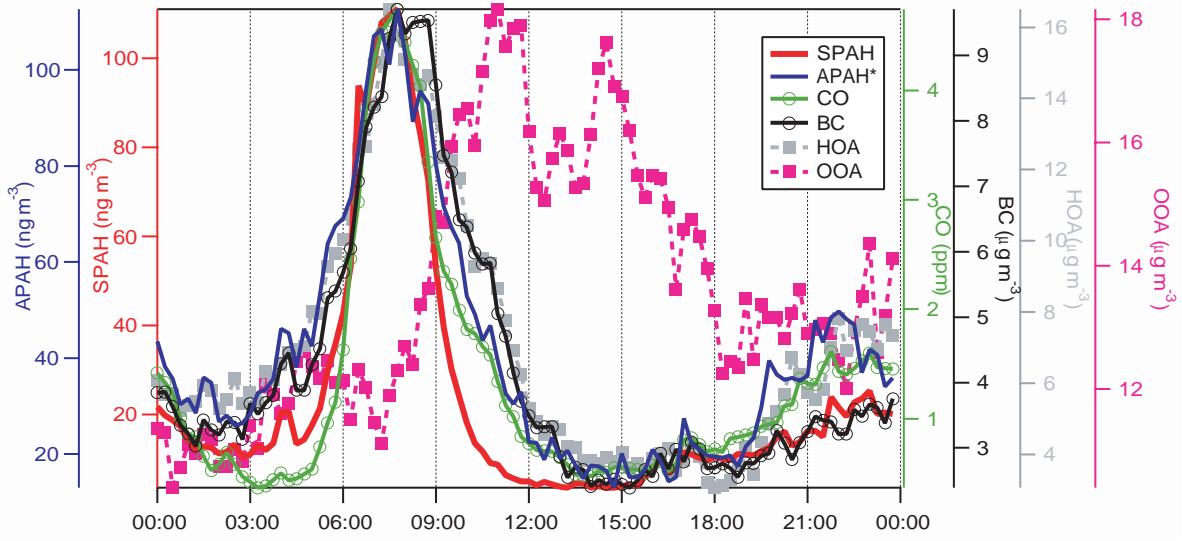

Fig. 6. Non-holiday weekday and weekend diurnal cycles of SPAH, APAH*, CO, BC, HOA, and OOA, each on its own scale.

The presence of triphenylbenzene and retene suggest that other sources also contribute to ambient PAHs in the MCMA. The high concentrations of triphenylbenzene at night are an indicator of garbage burning (Simoneit et al., 2005; Tong et al., 1984), a common nighttime activity in the MCMA. Concentrations of retene, a wood smoke marker (Ramdahl, 1983), are especially high on 27 April (not shown), when a forest fire burned for one hour on a nearby hill, Cerro de Estrella, starting at $\sim 18: 00$.

\subsection{PAH transformations}

Figure 6 shows diurnal cycles of SPAH, APAH*, CO, BC, hydrocarbon-like organic aerosol (HOA), and oxidized organic aerosol (OOA) averaged over 20 non-holiday weekdays. HOA is an indicator of freshly emitted particles, which are likely to be primary combustion aerosols in Mexico City, while OOA is a highly oxygenated aerosol, which is likely to be secondary organic aerosols from the photooxidation of aromatics and other precursors (Zhang et al., 2005a, c). OOA may also be associated with biomass burning emissions during the latter part of the campaign. Note that the y-axes start at the background concentration of each pollutant, not at zero. While $\mathrm{APAH}^{*}$, SPAH, CO, BC, and HOA concentrations rise in concert starting at 06:00 each morning, SPAH falls off much more quickly and diverges from $\mathrm{APAH}^{*}, \mathrm{CO}$, and $\mathrm{BC}$ at 09:00.

There are two hypotheses that could most likely explain the faster decay of SPAH relative to other indicators of vehicle emissions. The timing of the decay in SPAH concentrations, i.e. during the hours of the most active photochemistry in Mexico City, suggests that a photochemical mechanism may be responsible. First, coating of PAH-containing particles by condensation of secondary inorganic or organic aerosol or of semi-volatile compounds that were emitted at high temperature, such as cooking oil, could shield the PAHs from detection by photoionization. Electron microscopy of individual particles collected during the field campaign in- dicates that extensive processing of soot particles, including condensation of sulfate, can occur within $30 \mathrm{~min}$ to several hours (Johnson et al., 2005). For PAHs to be detected by photoionization, electrons must be ejected from the molecules and must be able to escape from the surface of the particle. Coating of PAH-containing particles could reduce the SPAH signal by making it less likely for PAHs to be photoionized or for ejected electrons to escape the particle.

Previous experiments have shown that paraffin coatings of 30-60 nm completely inhibit the photoionization signal (Niessner et al., 1990). Sufficient ammonium nitrate and secondary organic aerosol (SOA) may be produced in Mexico City's atmosphere to coat primary particles and at least partially inhibit the detection of surface-bound PAHs by photoionization. The following analysis assumes that inorganic aerosol and SOA condense on preexisting particles, rather than homogeneously nucleate, which is consistent with observations (Dunn et al., 2004). During the late morning, OOA reaches $6 \mu \mathrm{g} \mathrm{m}^{-3}$ above its background value (Fig. 6). If we assume that OOA represents SOA and has a density of $1.1 \mathrm{~g} \mathrm{~cm}^{-3}$ (Bahreini et al., 2005), then the excess OOA is equivalent to a volume concentration of $6 \times 10^{-12} \mathrm{~m}^{3} \mathrm{~m}^{-3}$. Divided over a maximum aerosol surface area of $1 \times 10^{-5} \mathrm{~cm}^{2} \mathrm{~cm}^{-3}$ estimated from the AMS measurements, this amount of SOA can coat the particles to a thickness of $6 \mathrm{~nm}$. Ammonium nitrate concentrations, which share a similar diurnal pattern to that of OOA, reach $12 \mu \mathrm{g} \mathrm{m}^{-3}$ above background in the late morning (Salcedo et al., 2006) and can contribute an additional $7 \mathrm{~nm}$ of thickness to the coating. The density of inorganic aerosol is assumed to be $1.7 \mathrm{~g} \mathrm{~cm}^{-3}$ (Bahreini et al., 2005). The fractal nature of primary particles (DeCarlo et al., 2004; Slowik et al., 2004; Zhang et al., 2005b) and unknown division of surface area between primary and secondary aerosol contribute uncertainty to this estimate. Although the total calculated coating thickness of $13 \mathrm{~nm}$ is only an approximation, it is of the order of magnitude needed to suppress, at least partially, the photoionization signal. 
Additionally, we have performed an exploratory laboratory experiment with the photoionization aerosol sensor and found that its response dropped by a factor of ten when soot particles were coated with oleic acid, while the AMS response did not change. The magnitude of surface coating and its relevance to ambient conditions were not characterized in this exploratory experiment.

The estimated size distributions of individual PAH masses, presented by Dzepina et al. $(2006)^{1}$ also support the idea that particles containing PAHs are coated, or at least grow in size, throughout the day. In the morning between 05:00 and 09:00, the modes of the size distributions of the PAHs at $m / z$ 's 202 and 226 occur at 350 and $200 \mathrm{~nm}$, respectively. In the afternoon between 14:00 and 18:00, the size distributions of these PAHs grow to larger diameters, $500-800 \mathrm{~nm}$. The shift to larger diameters, which is observed for all species in the city, is likely due to coagulation and condensation of secondary aerosol on preexisting particles (Dzepina et al., 2006 ${ }^{1}$ ).

The second hypothesis is that heterogeneous reactions of PAHs on the surfaces of particles may be responsible for the faster decay of SPAH versus other related pollutants. In the gas phase, the dominant loss process of PAHs during the daytime is reaction with the $\mathrm{OH}$ radical (Arey, 1998; Atkinson and Arey, 1994). In the particle phase, PAHs may undergo photolysis or reaction with oxidants such as $\mathrm{OH}$, ozone, nitrogen oxides, and nitric acid; and the rate of reaction depends on the nature of the underlying particles and meteorological factors (Behymer and Hites, 1988; Calvert et al., 2002; Finlayson-Pitts and Pitts, 2000; Kamens et al., 1986, 1988, 1985). Recent laboratory experiments suggest that $\mathrm{OH}$ addition to pyrene and subsequent reactions can lead to its removal from particles, in the form of volatile products (Molina et al., 2004). The $\mathrm{OH}$ reactivities of $11 \mathrm{PAHs}$ adsorbed on graphite particles have been found to be similar across the different species (Esteve et al., 2004), and heterogeneous reaction with $\mathrm{OH}$ rather than $\mathrm{NO}_{2}$ dominates losses of particle-phase PAHs (Esteve et al., 2006). As reaction with $\mathrm{OH}$ is the dominant loss process of gas-phase PAHs (Atkinson and Arey, 1994), we therefore investigate the heterogeneous reaction rate of $\mathrm{OH}$ with particle-phase PAHs to determine its role in the loss of PAHs in Mexico City. Heterogeneous oxidation by ozone may also be an important sink for PAHs (Donaldson et al., 2005), so the results presented here represent a lower limit of their reactive decay.

The analysis focuses on the period 09:00-10:00, when SPAH concentrations diverge from the others (Fig. 6). The predicted heterogeneous reaction rate $R_{\text {het }}$ is

$R_{\text {het }}=\frac{\omega \gamma}{4} A[\mathrm{OH}]$

where $\omega$ is the mean thermal velocity of $\mathrm{OH}\left(\mathrm{cm} \mathrm{s}^{-1}\right), \gamma$ is the heterogeneous reaction probability, $A$ is the surface area concentration of PAHs $\left(\mathrm{cm}^{2} \mathrm{~cm}^{-3}\right)$, and $[\mathrm{OH}]$ is the $\mathrm{OH}$ concentration (molec $\mathrm{cm}^{-3}$ ) (Bertram et al., 2001; Ravishankara, 1997). At $298 \mathrm{~K}$, the mean thermal velocity of
$\mathrm{OH}$ is $66100 \mathrm{~cm} \mathrm{~s}^{-1}$. We assume a reaction probability of 0.5 , which is consistent with experimental data for PAHs (Bertram et al., 2001).

At 09:00, the typical weekday SPAH concentration is $50 \mathrm{ng} \mathrm{m}^{-3}$. Based on PAH speciation profiles during the morning hours, the average molecular mass of the mixture is $258 \mathrm{~g} \mathrm{~mol}^{-1}$, so the corresponding surface PAH density is $1.2 \times 10^{14} \mathrm{molec}^{-3}$. Assuming a molecular cross section of $1 \mathrm{~nm}^{2}$ corresponding to benzo[a]pyrene (Karcher and Fordham, 1987), whose molecular mass is close to the average, we obtain a surface area PAH concentration of $1.2 \times 10^{-6} \mathrm{~cm}^{2} \mathrm{~cm}^{-3}$. For comparison, this value is $\sim 10 \%$ of the total surface area estimated from the AMS of $\sim 10^{-5} \mathrm{~cm}^{2} \mathrm{~cm}^{-3}$ during 09:00-10:00. Given a typical $\mathrm{OH}$ concentration in Mexico City at 09:00 of $1.4 \times 10^{6}$ molec $\mathrm{cm}^{-3}$ (Shirley et al., 2005; Volkamer et al., 2005), the resulting $R_{\text {het }}$ predicted by Eq. (1) is 14000 molec $\mathrm{cm}^{3} \mathrm{~s}^{-1}$.

The ratio of the typical PAH concentration at 09:00 to $R_{\text {het }}$ gives a characteristic lifetime of $2.3 \mathrm{~h}$ for heterogeneous reaction of $\mathrm{OH}$ with particulate PAHs. Given the uncertainty in reaction probability and other inputs to Eq. (1), we cannot rule out heterogeneous reactions as a mechanism for PAH loss. PAH reaction products, such as quinones, hydroxylPAHs, and nitro-PAHs were not found in the AMS signal (Dzepina et al., $2006^{1}$ ), but at this point in its development, the AMS is not specific or sensitive enough to detect them at the very low expected concentrations. However, because

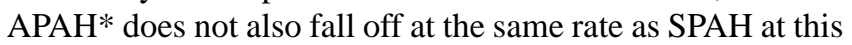
time of day, coating of the particles is a more likely explanation for the rapid decay of SPAH.

Another factor to be considered in these analyses is the semi-volatile nature of PAHs and their ability to repartition between gaseous and particulate forms (Allen et al., 1996). Some PAHs present on the surfaces of freshly emitted combustion particles may slowly desorb from the particles as ambient temperatures increase in the late morning. This phenomenon may contribute to the faster decay of the SPAH versus APAH* signal, if it involves PAHs that are detected by the PAS but not by the AMS, i.e. three-ring PAHs. Improved measurement techniques, especially at high time resolution for the smaller particle-phase PAHs, are needed to explore this hypothesis further.

\section{Conclusions}

Particulate PAH concentrations were measured by three different methods in Mexico City in April 2003: analysis of time-integrated filters, aerosol photoionization, and aerosol mass spectrometry. Speciated measurements suggest that motor vehicles are the predominant daytime source of PAHs and that wood and garbage burning are important nighttime sources. Particulate PAH concentrations are correlated with both $\mathrm{CO}$ and naphthalene. During the morning rush hour, total particulate PAH concentrations rise to a maximum 
of $\sim 110 \mathrm{ng} \mathrm{m}^{-3}$ between 07:30-08:00 and then decrease throughout the remainder of the morning to $\sim 20 \mathrm{ng} \mathrm{m}^{-3}$ in the afternoon. Overnight concentrations rise as high as $50 \mathrm{ng} \mathrm{m}^{-3}$. The more rapid decrease in surface versus bulk PAH concentrations during the late morning suggests that freshly emitted combustion-related particles are quickly coated by secondary aerosol material in Mexico City's atmosphere, and may also be transformed by heterogeneous reactions.

These results have important implications for public health and for climate. The diurnal pattern of ambient concentrations implies that exposure to PAHs will be much higher during the morning rush hour compared to the rest of the day. The rapid transformation of particle-phase PAHs during the morning suggests that the toxicity of fresh versus aged particles may differ. If PAHs are coated by other compounds, their bioavailability may decrease. Likewise, rapid coating of primary soot particles suggests that internally mixed particles containing black carbon cores will be prevalent in the outflow of Mexico City, which will lead to enhanced absorption of radiation and thus a larger perturbation of the regional radiation balance by these particles.

Acknowledgements. We are grateful to R. Ramos of RAMA, S. Blanco and F. Angeles of CENICA, and R. Atkinson. This research was supported by funds from the Alliance for Global Sustainability and the Mexican Metropolitan Environmental Commission to the Integrated Program on Urban, Regional and Global Air Pollution at MIT. We also acknowledge funding from the NSF Atmospheric Chemistry Program, Grants ATM-0308748 and ATM-0528634, and from the DOE Atmospheric Sciences Program, Grant DE-FG02-05ER63981. K. Dzepina is a recipient of an Advanced Study Program (ASP) Fellowship from the National Center for Atmospheric Research.

Edited by: C. E. Kolb

\section{References}

Allen, J. O., Dookeran, N. M., Smith, K. A., Sarofim, A. F., Taghizadeh, K., and LaFleur, A. L.: Measurement of polycyclic aromatic hydrocarbons associated with size-segregated atmospheric aerosols in Massachusetts, Environ. Sci. Technol., 30, 1023-1031, 1996.

Arey, J.: Atmospheric reactions of PAHs including formation of nitroarenes, in: The Handbook of Environmental Chemistry, edited by: Neilson, A. H., vol. 3, part I, Springer, Berlin, 1998.

Atkinson, R. and Arey, J.: Atmospheric chemistry of gas-phase polycyclic aromatic hydrocarbons: formation of atmospheric mutagens, Environmental Health Perspectives, 102, 117-126, 1994.

Bahreini, R., Keywood, M. D., Ng, N. L., Varutbangkul, V., Gao, S., Flagan, R. C., Seinfeld, J. H., Worsnop, D. R., and Jimenez, J. L.: Measurements of secondary organic aerosol from oxidation of cycloalkenes, terpenes, and m-xylene using an Aerodyne aerosol mass spectrometer, Environ. Sci. Technol., 39, 5674-5688, 2005.
Behymer, T. D. and Hites, R. A.: Photolysis of polycyclic aromatic hydrocarbons adsorbed on fly ash, Environ. Sci. Technol., 22, 1311-1319, 1988.

Benner, B. A., Gordon, G. E., and Wise, S. A.: Mobile sources of atmospheric polycyclic aromatic hydrocarbons: A roadway tunnel study, Environ. Sci. Technol., 23, 1269-1278, 1989.

Bertram, A. K., Ivanov, A. V., Hunter, M., Molina, L. T., and Molina, M. J.: The reaction probability of $\mathrm{OH}$ on organic surfaces of tropospheric interest, J. Phys. Chem. A, 105, 9415-9421, 2001.

Calvert, J. G., Atkinson, R., Becker, K. H., Kamens, R. M., Seinfeld, J. H., Wallington, T. J., and Yarwood, G.: The Mechanisms of Atmospheric Oxidation of Aromatic Hydrocarbons, Oxford University Press, New York, 2002.

Chandra, S., Satheesh, S. K., and Srinivasan, J.: Can the state of mixing of black carbon aerosols explain the mystery of 'excess' atmospheric absorption?, Geophys. Res. Lett., 31, L19109, doi:10.1029/2004GL020662, 2004.

Conant, W. C., Seinfeld, J. H., Wang, J., Carmichael, G. R., Tang, Y. H., Uno, I., Flatau, P. J., Markowicz, K. M., and Quinn, P. K.: A model for the radiative forcing during ACE-Asia derived from CIRPAS Twin Otter and R/V Ronald H. Brown data and comparison with observations, J. Geophys. Res., 108, 8661, doi:10.1029/2003JD003260, 2003.

de Foy, B., Caetano, E., Magaña, V., Zitacuaro, A., Cárdenas, B. Retama, A., Ramos, R., Molina, L. T., and Molina, M. J.: Mexico City basin wind circulation during the MCMA-2003 field campaign, Atmos. Chem. Phys., 5, 2267-2288, 2005.

DeCarlo, P., Slowik, J. G., Worsnop, D. R., Davidovits, P., and Jimenez, J. L.: Particle morphology and density characterization by combined mobility and aerodynamic diameter measurements. Part I: theory, Aerosol Sci. Technol., 38, 1185-1205, 2004.

Denissenko, M. F., Pao, A., Tang, M., and Pfeifer, G. P.: Preferential formation of benzo $[a]$ pyrene adducts at lung cancer mutational hotspots in P53, Science, 18, 430-432, 1996.

Donaldson, D. J., Mmereki, B. T., Chaudhuri, S. R., Handley, S., and $\mathrm{Oh}, \mathrm{M}$.: Uptake and reaction of atmospheric organic vapours on organic films, Faraday Discuss., 130, 227-239, 2005.

Dunn, M., Jimenez, J. L., Baumgardner, D., Castro, T., McMurry, P. H., and Smith, J. N.: Measurements of Mexico City nanoparticle size distributions: observations of new particle formation and growth, Geophys. Res. Lett., 31, L10102, doi:10.1029/2004GL019483, 2004.

Esteve, W., Budzinski, H., and Villenave, E.: Heterogeneous reactivity of $\mathrm{OH}$ radicals with phenanthrene, Polycyclic Aromatic Compounds, 23, 441-456, 2003.

Esteve, W., Budzinski, H., and Villenave, E.: Relative rate constants for the heterogeneous reactions of $\mathrm{OH}, \mathrm{NO}_{2}$ and $\mathrm{NO}$ radicals with polycyclic aromatic hydrocarbons adsorbed on carbonaceous particles. Part 1: PAHs adsorbed on 1-2 mm calibrated graphite particles, Atmos. Environ., 38, 6063-6072, 2004

Esteve, W., Budzinski, H., and Villenave, E.: Relative rate constants for the heterogeneous reactions of $\mathrm{NO}_{2}$ and $\mathrm{OH}$ radicals with polycyclic aromatic hydrocarbons adsorbed on carbonaceous particles. Part 2: PAHs adsorbed on diesel particulate exhaust SRM 1650a, Atmos. Environ., 40, 201-211, 2006.

Finlayson-Pitts, B. J. and Pitts, J. N.: Chemistry of the Upper and Lower Atmosphere, Academic Press, San Diego, CA, 2000.

Hannigan, M. P., Cass, G. R., Penman, B. W., Crespi, C. L., 
Lafleur, A. L., Busby, W. F., Thilly, W. G., and Simoneit, B. R. T.: Bioassay-directed chemical analysis of Los Angeles airborne particulate matter using a human cell mutagenicity assay, Environ. Sci. Technol., 32, 3502-3514, 1998.

Hart, K. M., McDow, S. R., Giger, W., Steiner, D., and Burthscher, H.: The correlation between in-situ, real-time aerosol photoemission intensity and particulate polycyclic aromatic hydrocarbon concentration in combustion aerosols, Water, Air, Soil Pollut., 68, 75-90, 1993.

Jacobson, M. Z.: Strong radiative heating due to the mixing state of black carbon in atmospheric aerosols, Nature, 409, 695-697, 2001.

Jayne, J. T., Leard, D. C., Zhang, X., Davidovits, P., Smith, K. A., Kolb, C. E., and Worsnop, D. R.: Development of an aerosol mass spectrometer for size and composition analysis of submicron particles, Aerosol Sci. Technol., 33, 49-70, 2000.

Jensen, T. E. and Hites, R. A.: Aromatic diesel emissions as a function of engine conditions, Anal. Chem., 55, 594-599, 1983.

Jimenez, J. L., Jayne, J. T., Shi, Q., Kolb, C. E., Worsnop, D. R., Yourshaw, I., Seinfeld, J. H., Flagan, R. C., Zhang, X., Smith, K. A., Morris, J., and Davidovits, P.: Ambient aerosol sampling with an aerosol mass spectrometer, J. Geophys. Res., 108, 84258438, 2003.

Johnson, K. S., Zuberi, B., Molina, L. T., Molina, M. J., Iedema, M. J., Cowin, J. P., Gaspar, D. J., Wang, C., and Laskin, A.: Processing of soot in an urban environment: case study from the Mexico City Metropolitan Area, Atmos. Chem. Phys., 5, 30333043, 2005.

Jones, C. C., Chughtai, A. R., Murugaverl, B., and Smith, D. M.: Effects of air/fuel combustion ratio on the polycyclic aromatic hydrocarbon content of carbonaceous soots from selected fuels, Carbon, 42, 2471-2484, 2004.

Kamens, R. M., Fulcher, J. N., and Zhishi, G.: Effects of temperature on wood soot PAH decay in atmospheres with sunlight and low $\mathrm{NO}_{\mathrm{x}}$, Atmos. Environ., 20, 1579-1587, 1986.

Kamens, R. M., Guo, Z., Fulcher, J. N., and Bell, D. A.: Influence of humidity, sunlight, and temperature on the daytime decay of polyaromatic hydrocarbons on atmospheric soot particles, Environ. Sci. Technol., 22, 103-108, 1988.

Kamens, R. M., Perry, J. M., Saucy, D. A., Bell, D. A., Newton, D. L., and Brand, B.: Factors which influence polycyclic aromatic hydrocarbon decomposition on wood smoke particles, Environ. Int., 11, 131-136, 1985.

Karcher, W. and Fordham, R. J.: Spectral Atlas of Polycyclic Aromatic Compounds, Kluwer Academic Publishers, Dordrecht, The Netherlands, 1987.

Lim, L. H., Harrison, R. M., and Harrad, S.: The contribution of traffic to atmospheric concentrations of polycyclic aromatic hydrocarbons, Environ. Sci. Technol., 33, 3538-3542, 1999.

Lu, R., Wu, J., Turco, R. P., Winer, A. M., Atkinson, R., Arey, J., Paulson, S. E., Lurmann, F. W., Miguel, A. H., and EigurenFernandez, A.: Naphthalene distributions and human exposure in Southern California, Atmos. Environ., 39, 489-507, 2004.

Marr, L. C., Black, D. R., and Harley, R. A.: Formation of photochemical air pollution in central California 1. Development of a revised motor vehicle emission inventory, J. Geophys. Res., 107, 4047, doi:10.1029/2001JD000689, 2002.

Marr, L. C., Grogan, L. A., Worhrnschimmel, H., Molina, L. T., Molina, M. J., Smith, T. J., and Garshick, E.: Vehicle traffic as a source of particulate polycyclic aromatic hydrocarbon exposure in Mexico City, Environ. Sci. Technol., 38, 2584-2592, 2004.

Marr, L. C., Kirchstetter, T. W., Harley, R. A., Miguel, A. H., Hering, S. V., and Hammond, S. K.: Characterization of polycyclic aromatic hydrocarbons in motor vehicle fuels and exhaust emissions, Environ. Sci. Technol., 33, 3091-3099, 1999.

McDow, S. R., Giger, W., Burthscher, H., Schmidt-Ott, A., and Siegmann, H. C.: Polycyclic aromatic hydrocarbons and combustion aerosol photoemission, Atmos. Environ., 24A, 29112916, 1990.

Miguel, A. H., Kirchsetter, T. W., Harley, R. A., and Hering, S. V.: On-road emissions of particulate polycyclic aromatic hydrocarbons and black carbon from gasoline and diesel vehicles, Environ. Sci. Technol., 32, 450-455, 1998.

Molina, M. J., Ivanov, A. V., Trakhtenberg, S., and Molina, L. T.: Atmospheric evolution of organic aerosol, Geophys. Res. Lett., 31, L22104, doi:10.1029/2004GL020910, 2004.

Nielsen, T.: Traffic contribution of polycyclic aromatic hydrocarbons in the center of a large city, Atmos. Environ., 30, 34813490, 1996.

Niessner, R.: The chemical response of the photo-electric aerosol sensor (PAS) to different aerosol systems, J. Aerosol Sci., 17, 705-714, 1986.

Niessner, R., Hemmerich, B., and Wilbring, P.: Aerosol photoemission for quantification of polycyclic aromatic hydrocarbons in simple mixtures adsorbed on carbonaceous and sodium chloride aerosols, Anal. Chem., 52, 2071-2074, 1990.

Ramdahl, T.: Retene-a molecular marker of wood combustion in ambient air, Nature, 306, 580-582, 1983.

Ravishankara, A. R.: Heterogeneous and multiphase chemistry in the troposphere, Science, 5315, 1058-1065, 1997.

Reisen, F. and Arey, J.: Atmospheric reactions influence seasonal PAH and nitro-PAH concentrations in the Los Angeles basin, Environ. Sci. Technol., 39, 64-73, 2005.

Salcedo, D., Onasch, T. B., Dzepina, K., Canagaratna, M. R., Zhang, Q., Huffman, J. A., DeCarlo, P. F., Jayne, J. T., Mortimer, P., Worsnop, D. R., Kolb, C. E., Johnson, K. S., Zuberi, B., Marr, L. C., Volkamer, R., Molina, L. T., Molina, M. J., Cardenas, B., Bernabé, R. M., Márquez, C., Gaffney, J. S., Marley, N. A., Laskin, A., Shutthanandan, V., Xie, Y., Brune, W., Lesher, R., Shirley, T., and Jimenez, J. L.: Characterization of ambient aerosols in Mexico City during the MCMA-2003 campaign with Aerosol Mass Spectrometry: results from the CENICA supersite, Atmos. Chem. Phys., 6, 925-946, 2006.

Sanderson, E. G. and Farant, J.-P.: Atmospheric size distribution of PAHs: evidence of a high-volume sampling artifact, Environ. Sci. Technol., 39, 7631-7637, 2005.

Sasaki, J. C., Arey, J., Eastmond, D. A., Parks, K. K., and Grosovsky, A. J.: Genotoxicity induced in human lymphoblasts by atmospheric reaction products of naphthalene and phenanthrene, Mutation Research - Genetic Toxicology and Environmental Mutagenesis, 393, 23-35, 1997.

Schauer, C., Niessner, R., and Pöschl, U.: Polycyclic aromatic hydrocarbons in urban air particulate matter: decadal and seasonal trends, chemical degradation, and sampling artifacts, Environ. Sci. Technol., 37, 2861-2868, 2003.

Secretaría del Medio Ambiente, Inventario de Emisiones a la Atmosfera: Zona Metropolitana del Valle de Mexico 2000, Gobierno del Distrito Federal, Mexico, 2003. 
Seki, K.: Ionization energies of free molecules and molecular solids, Mol. Cryst. Liq. Cryst., 171, 255-270, 1989.

Shirley, T. R., Brune, W. H., Ren, X., Mao, J., Lesher, R., Cardenas, B., Volkamer, R., Molina, L. T., Molina, M. J., Lamb, B., Velasco, E., Jobson, T., and Alexander, M.: Atmospheric oxidation in the Mexico City Metropolitan Area (MCMA) during April 2003, Atmos. Chem. Phys. Discuss., 5, 6041-6076, 2005.

Siegmann, K. and Siegmann, H. C.: Fast and reliable "in situ" evaluation of particles and their surfaces with special reference to diesel exhaust, SAE Technical Paper Series, 2000-01-1995, 1-7, 2000.

Simoneit, B. R. T., Medeiros, P. M., and Didyk, B. M.: Combustion products of plastics as indicators for refuse burning in the atmosphere, Environ. Sci. Technol., 29, 6961-6970, 2005.

Slowik, J. G., Stainken, K., Davidovits, P., Williams, L. R., Jayne, J. T., Kolb, C. E., Worsnop, D. R., Rudich, Y., DeCarlo, P. F., and Jimenez, J. L.: Particle morphology and density characterization by combined mobility and aerodynamic diameter measurements. Part 2: Application to combustion-generated soot aerosols as a function of fuel equivalence ratio, Aerosol Sci. Technol., 38, 1206-1222, 2004.

Takada, H., Onda, T., and Ogura, N.: Determination of polycyclic aromatic hydrocarbons in urban street dusts and their source materials by capillary gas chromatography, Environ. Sci. Technol., 24, 1179-1186, 1990.

Tancell, P. J., Rhead, M. M., Pemberton, R. D., and Braven, J.: Survival of polycyclic aromatic hydrocarbons during diesel combustion, Environ. Sci. Technol., 29, 2871-2876, 1995.

Tong, H. Y., Shore, D. L., Karasek, F. W., Helland, P., and Jellum, E.: Identification of organic-compounds obtained from incineration of municipal waste by high-performance liquidchromatographic fractionation and gas-chromatography massspectrometry, J. Chromatography, 285, 423-441, 1984.

Velasco, E., Siegmann, P., and Siegmann, H. C.: Exploratory study of particle-bound polycyclic aromatic hydrocarbons in different environments in Mexico City, Atmos. Environ., 38, 4957-4968, 2004.

Volkamer, R., Molina, L. T., Molina, M. J., Shirley, T., and Brune, W. H.: DOAS measurement of glyoxal as an indicator for fast VOC chemistry in urban air, Geophys. Res. Lett., 32, L08806, doi:10.1029/2005GL022616, 2005.

Wallace, L.: Real-time monitoring of particles, PAH, and CO in an occupied townhouse, Applied Occupational and Environmental Hygiene, 15, 39-47, 2000.
Wasserkort, R., Hartmann, A., Widmer, R. M., and Burthscher, H.: Correlation between on-line PAH detection in airborne particle samples and their bacterial genotoxicity, Ecotoxicology and Environmental Safety, 40, 126-136, 1996.

Watson, J. G. and Chow, J. C.: A wintertime $\mathrm{PM}_{2.5}$ episode at the Fresno, CA supersite, Atmos. Environ., 36, 465-475, 2002.

Westerholm, R. N., Almen, J., and Li, H.: Chemical and biological characterization of particulate-, semivolatile-, and gas-phaseassociated compounds in diluted heavy-duty diesel exhausts: a comparison of three different semi-volatile-phase samplers, Environ. Sci. Technol., 25, 332-338, 1991.

Westerholm, R. N., Alsberg, T. E., Frommelin, A. B., Strandell, M. E., Rannug, U., Winquist, L., Grigoriadis, V., and Egeback, K.-E.: Effect of fuel polycyclic aromatic hydrocarbon content on the emissions of polycyclic aromatic hydrocarbons and other mutagenic substances from a gasoline-fueled automobile, Environ. Sci. Technol., 22, 925-930, 1988.

Williams, P. T., Abbass, M. K., Andrews, G. E., and Bartle, K. D.: Diesel particulate emissions: the role of unburned fuel, Combustion and Flame, 75, 1-24, 1986.

Zhang, Q., Alfarra, M. R., Worsnop, D. R., Allan, J. D., Coe, H., Canagaratna, M. R., and Jimenez, J. L.: Deconvolution and quantification of hydrocarbon-like and oxygenated organic aerosols based on aerosol mass spectrometry, Environ. Sci. Technol., 39, 4938-4952, 2005a.

Zhang, Q., Canagaratna, M. R., Jayne, J. T., Worsnop, D. R., and Jimenez, J. L.: Time and size-resolved chemical composition of submicron particles in Pittsburgh - implications for aerosol sources and processes, J. Geophys. Res., 110, D07S09, doi:10.1029/2004JD004649, 2005 b.

Zhang, Q., Worsnop, D. R., Canagaratna, M. R., and Jimenez, J. L.: Hydrocarbon-like and oxygenated organic aerosols in Pittsburgh: insights into sources and processes of organic aerosols, Atmos. Chem. Phys., 5, 3289-3311, 2005c.

Zielinska, B., Sagebiel, J., Arnott, W. P., Rogers, C. F., Kelly, K. E., Wagner, D. A., Lighty, J. S., Sarofim, A. F., and Palmer, G.: Phase and size distribution of polycyclic aromatic hydrocarbons in diesel and gasoline vehicle emissions, Environ. Sci. Technol., 38, 2557-2567, 2004a.

Zielinska, B., Sagebiel, J., McDonald, J. D., Whitney, K., and Lawson, D. R.: Emission rates and comparative chemical composition from selected in-use diesel and gasoline-fueled vehicles, Journal of the Air and Waste Management Association, 54, 1138-1150, 2004b. 